\title{
Evaluation of MDR1 and MRPA genes expression in different types of dry cutaneous leishmaniasis
}

\author{
Maryam Fekrisoofiabadi , Meisam Fekri ${ }^{1}$, Alireza Moradabadi ${ }^{3}$, Reza Vahidi ${ }^{1}$, Morteza Khaleghi ${ }^{1}$, Maryam Ram ${ }^{1}$ \\ and Shahriar Dabiri ${ }^{*}$
}

\begin{abstract}
Objective: The resistance to antimony-containing glucantime is a major obstacle to successful treatment, especially in endemic areas. Looking the molecular mechanisms involved in this drug resistance will help in choosing the best treatment. The aim of this study was to evaluate the expression of multidrug-resistance 1 (MDR1) and multidrug-resistance protein A (MRPA) genes in acute, chronic non-lupoid, and chronic lupoid forms of dry type cutaneous leishmaniasis (DTCL).

Results: MDR1 gene was over-expressed as 14.4- and 1.56-folds in the chronic lupoid and acute forms compared with the chronic non-lupoid form, respectively. Results comparison showed $\mathrm{P}<0.05$ between the chronic non-lupoid and acute groups, $P<0.01$ between acute and chronic lupoid groups, and $P<0.001$ between the chronic non-lupoid and chronic lupoid groups. MRPA gene was over-expressed as 266 and 17.7-fold in the chronic lupoid and chronic non-lupoid forms compared with the acute form, respectively. Statistical analysis showed $P<0.01$ between the chronic non-lupoid and chronic lupoid groups, $P<0.05$ between acute and chronic non-lupoid groups, and $P<0.001$ between the acute and chronic lupoid groups.
\end{abstract}

Keywords: Multidrug-resistance 1, Multidrug-resistance protein A, Dry type cutaneous leishmaniasis, Real-time PCR

\section{Introduction}

Leishmaniasis, one of the most common diseases among humans and animals [1], is caused by different species of protozoan parasites of the genus Leishmania, especially Leishmania major and Leishmania tropica. According to the World Health Organization (WHO), leishmaniasis is endemic in 88 countries, and 12 million people are infected by various forms of this pathogen, with an annual incidence of 1-1.5 million people [2]. From the histopathological point of view, acute, chronic lupoid, and chronic non-lupoid forms have special

\footnotetext{
*Correspondence: dabiri12@yahoo.com

${ }^{1}$ Department of Pathology, Pathology and Stem Cell Research Center, Afzalipour Medical School, Kerman University of Medical Sciences, 22 Bahman Blvd, Kerman, Iran

Full list of author information is available at the end of the article
}

characteristics in terms of histiocyte and other inflammatory cells infiltration, presence of Leishman bodies and epithelioid granuloma [3-11]. Currently, quantitative real-time polymerase chain reaction (Real-time PCR) was developed for sensitive detection of different forms [12]. Also the FLASH-PCR used as a closed and sensitive method [13]. Considering the prevalence and complications of glucantime therapy in dry type cutaneous leishmaniasis (DTCL), the related drug resistance reports, and critical function of efflux pumps in resistance, the authors decided to use the Real-time PCR technique to determine the level of multidrug resistance protein 1 (MDR1) and multidrug-resistance protein A (MRPA) genes expression in acute, chronic non-lupoid, and chronic lupoid forms in paraffinized biopsy specimens. 


\section{Main text}

\section{Materials and methods}

Sample collection

In this study, paraffinized skin biopsy samples from 90 positive Leishmania tropica patients, who referred (2010-2015) to the Dermatopathology Department of Afzalipour Medical School (Kerman University of Medical Sciences, Iran) and received at least three courses of glucantime, were applied. After staining of corresponding sections with Hematoxylin and Eosin, these human samples were classified into three forms: acute $(n=30)$, chronic non-lupoid $(n=30)$, and chronic lupoid $(n=30)$. It should be noted that skin samples came from different locations such as hand, lower lip, face, forearm, nose, and leg.

\section{RNA extraction and CDNA synthesis}

RNAs were extracted from paraffinized tissue samples using RNeasy FFPE kit (Qiagen, Germany) and corresponding cDNAs were made according to the RevertAid first strand cDNA kit (Thermo, k1622) protocol. To remove the DNA from RNA, the DNase I (Thermo) was used and finally the quantity and quality of resultant RNAs were evaluated using NanoDrop (ND-2000 Thermo, USA) and gel electrophoresis, respectively.

\section{Primer design}

In the present study, three sets of primer pairs corresponding to Leishmania tropica were designed using the VECTOR NTI Bioinformatic software and were then approved by NCBI with the PRIMER BLAST. These primers were synthesized by Korean Bioneer Company. The beta-actin gene (as a reference) from previous study was used to normalize the data [14]. The used primers for MDR1-F/R, MRPA-F/R, and beta-actin-F/R are shown in Table 1.

\section{Real-time PCR assay}

To perform this assay, Gene Bio kit (Q9210) of Korea was used. For this purpose, $10 \mu \mathrm{L}$ of Qmaster mix (2x) with

Table 1 The used primers in Real-time PCR assay

\begin{tabular}{ll}
\hline Primers & Sequences $\left(\mathbf{5}^{\prime}-\mathbf{3}^{\prime}\right)$ \\
\hline MDR1.F & 5'-ATTGTCGCTTCTGGGGTTG-3' \\
MDR1.R & 5'-ATCGTGTCGCTTGTGTCAC-3' \\
MRPA.F & 5'-ATTACGTCCTGCAAGTCTGC-3' \\
MRPA.R & 5'-ATTGTCGCTTCTGGGGTTG-3' \\
Beta actin.F & 5'-ACCACCTTCAACTCCATCATG-3' \\
Beta actin.R & 5'-CTCCTTCTGCATCCTGTCG-3' \\
\hline
\end{tabular}

MDR1 Multidrug resistance protein 1, MRPA Multidrug-resistance protein A, $F$ Forward, $R$ Reverse
SYBR Green, $5 \mu \mathrm{L}$ of water, $1 \mu \mathrm{L}$ of forward primer, $1 \mu \mathrm{L}$ of reverse primer, $1 \mu \mathrm{L}$ of ROX dye, and $2 \mu \mathrm{L}$ of cDNA were mixed together. Amplification of desired fragments was performed using Applied Biosystem StepOne (ABI). The used program include: initial denaturation at $95{ }^{\circ} \mathrm{C}$ for $10 \mathrm{~min}(1 \mathrm{cycle})$, denaturation at $95{ }^{\circ} \mathrm{C}$ for $30 \mathrm{~s}, 66^{\circ} \mathrm{C}$ for $30 \mathrm{~s}$, and $72{ }^{\circ} \mathrm{C}$ for $30 \mathrm{~s}$ in 40 cycles. Using $\mathrm{CT}$ data $\left(2^{-\Delta \Delta c t}\right)$, the expression level of target genes was calculated in the three acute, chronic non-lupoid, and chronic lupoid forms of leishmaniasis. Finally the corresponding diagrams were drawn.

\section{Statistical analysis}

Using $t$ test and by comparing mean of genes expression, the differences between experimental groups (two by two) were analyzed. $\mathrm{P}<0.05$ was considered as statistically significant.

\section{Results}

Real-time PCR method was used to determine the alterations of MDR1 and MRPA genes in parasitic tissues of acute, chronic non-lupoid, and chronic lupoid forms (30 paraffinized biopsy samples for each form) of Leishmania tropica. Compared with chronic non-lupoid specimens, the expression of MDR1 gene in acute and chronic lupoid paraffinized specimens were 1.56- and 14.4-folds, respectively. On the other hand, the expression of MRPA gene in chronic non-lupoid and chronic lupoid specimens were 17.7- and 266-folds, respectively, compared with acute specimens (Fig. 1a, b). As is clear, these differences were significant (Fig. 1c, d).

\section{Discussion}

The control of Leishmania tropica is dependent on the immediate diagnosis and correct, timely, and effective treatment of patients. Despite some complications [15-18], chemotherapy, especially by pentavalent antimony compounds (like glucantime), is used more than other approaches. Limited information about underlying mechanisms has led to the emergence of resistance as a major factor affecting the treatment and control of cutaneous leishmaniasis, especially the urban type [1921 . Due to the importance of drug resistance and high financial and medical costs for patients, the need to new treatments is felt. It is also necessary to identify resistant genes and find solutions to prevent their genetic effects. P-glycoprotein and Multidrug resistance-related protein (MRP), members of ATP-binding cassette (ABC) transporters family, are coded by the MDR1 and MRPA genes. Indeed, they are ATP-dependent drug efflux pumps that can reduce drug accumulation in resistant cells [2, 21-25]. Accordingly, the purpose of present study was to evaluate the expression of MDR1 and MRPA genes in 

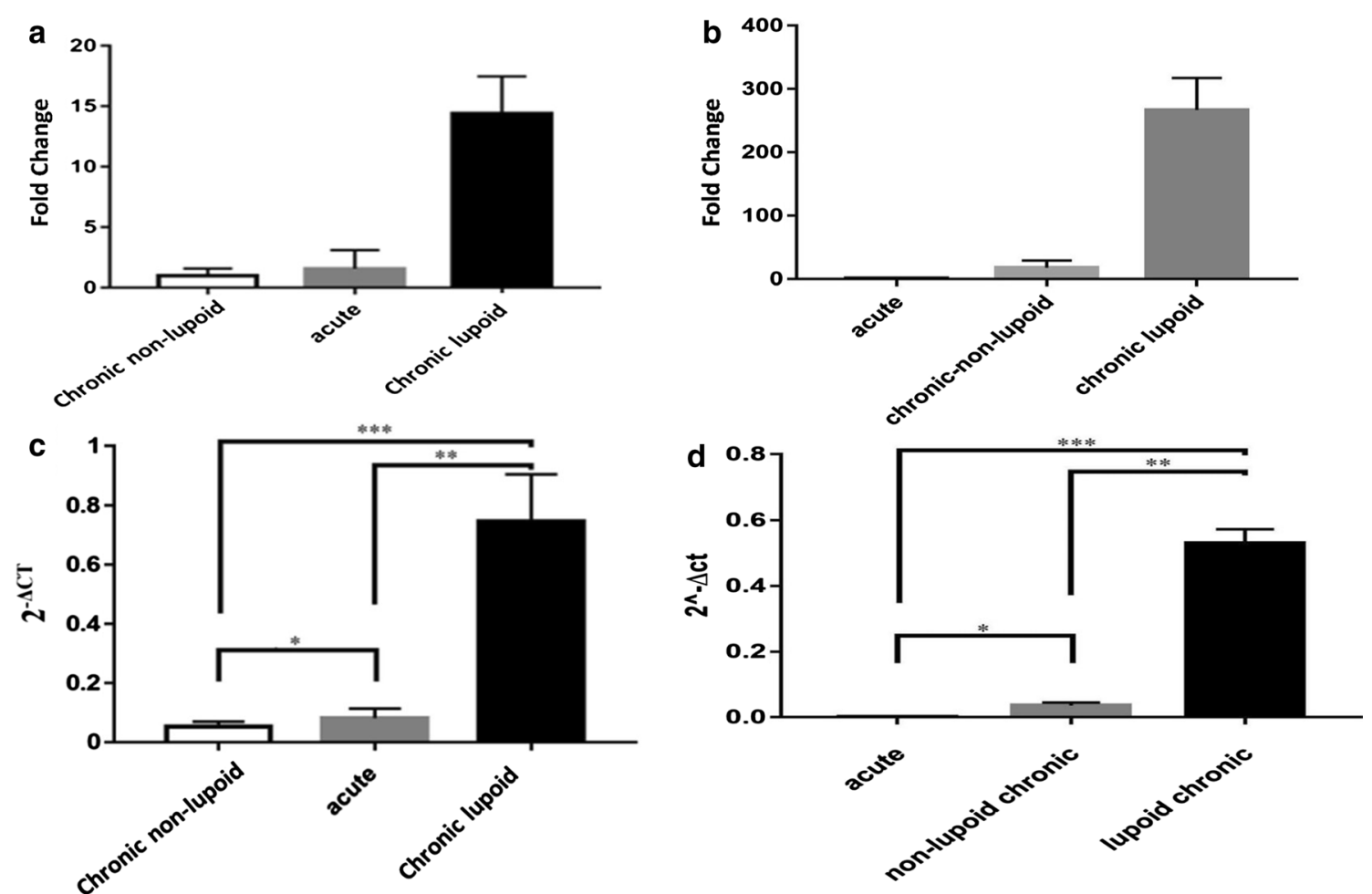

Fig. 1 a The relative expression of MDR1 gene in the acute and chronic lupoid groups in compared with chronic non-lupoid were 1.56 and 14.4, respectively. $\mathbf{b}$ The relative expression of MRPA gene in the chronic non-lupoid and chronic lupoid groups in compared with acute group were 17.7 and 266, respectively. c Column chart of changes in the expression of MDR1 gene in acute, chronic non-lupoid, and chronic lupoid forms of Leishmania tropica. ${ }^{*}, * *$, and ${ }^{* * *}$ show statistically significant difference between the chronic non-lupoid and acute groups $(P<0.05)$, between the acute and chronic lupoid groups $(P<0.01)$, and between the chronic non-lupoid and chronic lupoid groups $(P<0.001)$. $\mathbf{d}$ Column chart of changes in the expression of MRPA gene in acute, chronic non-lupoid, and chronic lupoid forms of Leishmania tropica. ${ }^{*},{ }^{* *}$, and ${ }^{* * *}$ show statistically significant difference between the chronic non-lupoid and acute groups $(P<0.05)$, between the acute and chronic lupoid groups $(P<0.001)$, and between the chronic non-lupoid and chronic lupoid groups $(P<0.01)$

acute, chronic non-lupoid, and chronic lupoid forms of Leishmaniasis using the Real-time PCR technique.

As presented in "Results" section, our findings showed that expression of MDR1 and MRPA in the chronic lupoid form was greater than chronic non-lupoid and acute forms. Contrary to our expectation, the level of MDR1 gene expression in the acute form was greater than chronic non-lupoid form (1.56-fold). Perhaps in this case, other genes and protein agents play a role in drug resistance. In line with this, 89 proteins were responsible for Leishmania major glucantime-resistance in a previous experiment [22]. For instance, the increased expression of ubiquitin and amino acid permease (AAP3) genes, increased activity of multidrug-resistance protein A (MRPA), protein tyrosine phosphatase (PTP), phosphoglycerate kinase (PGK), and the antagonists of the aquaglyceroporin (AQP1), mitogen activated protein kinase (MAPK), and calcineurin genes were probable causes of resistance. Similarly, Kazemi and co-workers identified antimony resistance markers in Leishmania tropica by cDNA-AFLP method [18].

The present work is the first study which compared the expression level of MDR1 and MRPA genes in acute, chronic non-lupoid, and chronic lupoid forms in the biopsy specimens of patients and also confirmed that the Real-time PCR method is a feasible method for investigating the resistance-related genes.

\section{Limitations}

Accurately detection of MRPA and MDR1 in biopsy samples help to treat better in case with leishmaniosis. Using the paraffin-embedded biopsy samples make our samples collection time short. But it's make the DNA extraction laboratories and effect on the quality of extracted DNA. In other hand to find better 
assumption of the resistance it's better to evaluate other mechanisms other than the cytoplasmic channels.

\begin{abstract}
Abbreviations
MDR1: multidrug-resistance 1; MRPA: multidrug-resistance protein A; DTCL: dry type cutaneous leishmaniasis; AAP3: amino acid permease; PTP: protein tyrosine phosphatase; PGK: phosphoglycerate kinase; AQP1: antagonists of the aquaglyceroporin; MAPK: mitogen activated protein kinase.
\end{abstract}

\section{Acknowledgements}

The authors would like to thank all friends and colleagues of Pathology and Stem Cell Research Center of Kerman University of Medical Sciences for their relentless hard work and efforts.

\section{Authors' contributions}

SD proposed the original concept and designed the experiment and supervised all aspects of the work. MFA., MF., AM, RV, MR, and MK equally participated in the data acquisition and analysis. All authors contributed to writing the manuscript. SD provided critical reviews in order to promote the manuscript. All authors ensure that this is the last version of manuscript for publication in BMC Research Notes journal. All authors read and approved the final manuscript.

\section{Funding}

No funding sources used in this study.

\section{Availability of data and materials}

Please contact corresponding author (SD) for data requests.

\section{Ethics approval and consent to participate}

The study approved in Ethical Committee of Kerman University of Medical Sciences. The Ethical Approval Code is IR.KMU.REC.1397.267.

\section{Consent for publication}

Not applicable.

\section{Competing interests}

Not applicable.

\section{Author details}

1 Department of Pathology, Pathology and Stem Cell Research Center, Afzalipour Medical School, Kerman University of Medical Sciences, 22 Bahman Blvd, Kerman, Iran. ${ }^{2}$ Department of Medicine, Montefiore New Rochelle Hospital, Albert Einstein College of Medicine, New York, USA. ${ }^{3}$ Department of Hematology, School of Para Medicine, Arak University of Medical Science, Arak, Iran.

Received: 17 September 2019 Accepted: 4 November 2019

Published online: 12 December 2019

\section{References}

1. Karami M, Doudi M, Setorki M. Assessing epidemiology of cutaneous leishmaniasis in Isfahan, Iran. J Vector Borne Dis. 2013;50(1):30.

2. Talari S, Kazemi B, Hooshyar H, Alizadeh R, Arbabi M, Mousavi G, et al. Identification of mutation for drug resistance gene in cutaneous leishmaniasis. Feyz J Kashan Univ Med Sci. 2012;16(3):235-9.

3. Meymandi SS, Javadi A, Dabiri S, Nadji M. Comparative histological and immunohistochemical changes of dry type cutaneous leishmaniasis after administration of meglumine antimoniate, imiquimod or combination therapy. Arch Iran Med. 2011;14(4):238.

4. Choi CM, Lerner EA. Leishmaniasis as an emerging infection. J Invest Derm Symp Proc. 2001. https://doi.org/10.1046/j.0022-202x.2001.00038.x

5. Garcia C, Poletti E, Crowson AN. Basosquamous carcinoma. J Am Acad Dermatol. 2009;60(1):137-43.
6. Salman SM, Rubeiz NG, Kibbi A-G. Cutaneous leishmaniasis: clinical features and diagnosis. Clin Dermatol. 1999;17(3):291-6.

7. Meymandi S, Dabiri S, Dabiri D, Crawford RI, Kharazmi A. A quantitative study of epidermal Langerhans cells in cutaneous leishmaniasis caused by Leishmania tropica. Int J Dermatol. 2004;43(11):819-23.

8. Garnier T, Croft SL. Topical treatment for cutaneous leishmaniasis. Curr Opin Investig Drugs. 2002;3:538-44.

9. Gurel MS, Ulukanligil M, Ozbilge H. Cutaneous leishmaniasis in Sanliurfa: epidemiologic and clinical features of the last four years (1997-2000). Int J Dermatol. 2002:41(1):32-7.

10. Oliveira-Neto MP, Mattos M, da Silva C, de Souza F, Fernandes O, Pirmez C. Leishmaniasis recidiva cutis in new world cutaneous leishmaniasis. Int J Dermatol. 1998;37(11):846-9.

11. Ardehali S, Sodeiphy M, Haghighi P, Rezai H, Vollum D. Studies on chronic (lupoid) leishmaniasis. Ann Trop Med Parasitol. 1980;74(4):439-45.

12. Fekri MA, Fekri ME, Moradabadi A, Vahidi R, Shamsi-Meymandi S, Dabiri $D$, Dabiri S. Ability of real-time PCR for differential diagnosis of various forms of cutaneous leishmaniasis: a comparative study with histopathology. BMC Research Notes. 2019;12(1):615.

13. Moradabadi AL, Farsinejad A, Fekri SM. Fast method for diagnosis of leishmania by PCR and FLASH PCR. J Arak Univ Med Sci. 2017;19(11):79-86.

14. Dabiri S, Amirpoor S. Design and validation of real-time PCR: quantitative diagnosis of common Leishmania species in Iran. Arch Iran Med. 2016;19(7):496

15. Almeida OLS, Santos JB. Advances in the treatment of cutaneous leishmaniasis in the new world in the last ten years: a systematic literature review. Anais brasileiros de Dermatol. 2011;86(3):497-506.

16. Tiuman TS, Santos AO, Ueda-Nakamura T, Dias Filho BP, Nakamura CV. Recent advances in leishmaniasis treatment. Int J|Infect Dis. 2011;15(8):e525-32.

17. Croft SL, Coombs GH. Leishmaniasis-current chemotherapy and recent advances in the search for novel drugs. Trends Parasitol. 2003;19(11):502-8.

18. Kazemi-Rad E, Mohebali M, Khadem-Erfan MB, Saffari M, Raoofian R, Hajjaran $\mathrm{H}$, et al. Identification of antimony resistance markers in Leishmania tropica field isolates through a CDNA-AFLP approach. Exp Parasitol. 2013;135(2):344-9.

19. Croft SL, Sundar S, Fairlamb AH. Drug resistance in leishmaniasis. Clin Microbiol Rev. 2006;19(1):111-26.

20. Thakur C, Narayan S, Ranjan A. Epidemiological, clinical \& pharmacological study of antimony-resistant visceral leishmaniasis in Bihar, India. Indian J Med Res. 2004;120(3):166.

21. Hadighi R, Mohebali M, Boucher P, Hajjaran H, Khamesipour A, Ouellette $M$. Unresponsiveness to glucantime treatment in Iranian cutaneous leishmaniasis due to drug-resistant Leishmania tropica parasites. PLoS medicine. 2006;3(5):e162.

22. Zarean M, Maraghi S, Hajjaran H, Mohebali M, Feiz-Hadad MH, Assarehzadegan MA. Comparison of proteome profiling of two sensitive and resistant field Iranian isolates of Leishmania major to Glucantime ${ }^{\circledR}$ by 2-dimensional electrophoresis. Iran J Parasitol. 2015;10(1):19.

23. Kumar D, Singh R, Bhandari V, Kulshrestha A, Negi NS, Salotra P. Biomarkers of antimony resistance: need for expression analysis of multiple genes to distinguish resistance phenotype in clinical isolates of Leishmania donovani. Parasitol Res. 2012;111(1):223-30.

24. Sundar S, More DK, Singh MK, Singh VP, Sharma S, Makharia A, et al. Failure of pentavalent antimony in visceral leishmaniasis in India: report from the center of the Indian epidemic. Clin Infect Dis. 2000;31(4):1104-7.

25. Plourde M, Coelho A, Keynan Y, Larios OE, Ndao M, Ruest A, et al. Genetic polymorphisms and drug susceptibility in four isolates of Leishmania tropica obtained from Canadian soldiers returning from Afghanistan. PLoS Negl Trop Dis. 2012;6(1):e1463.

\section{Publisher's Note}

Springer Nature remains neutral with regard to jurisdictional claims in published maps and institutional affiliations. 